\title{
What is the optimal cerebral perfusion pressure in children suffering from traumatic coma?
}

\author{
Iain R. Chambers, Ph.D., and Fenella J. Kirkham, M.B., B.Ch. \\ Regional Medical Physics Department, Newcastle General Hospital, Newcastle Upon Tyne; \\ and Department of Child Health, Southampton General Hospital, Southampton, United Kingdom
}

\begin{abstract}
Head injury is a major cause of death and disability in children. Despite advances in resuscitation, emergency care, intensive care monitoring, and clinical practices, there are few data demonstrating the predictive value of certain physiological variables regarding outcome in this patient population. Mean arterial blood pressure (MABP), intracranial pressure (ICP), and cerebral perfusion pressure $(\mathrm{CPP}=\mathrm{MABP}-\mathrm{ICP})$ are routinely monitored in patients in many neurological intensive care units throughout the world, but there is little evidence indicating that advances in care have been matched with corresponding improvements in outcome.

Nonetheless, there is evidence that hypotension immediately following head injury is predictive of early death, and many patients with these features die with clinical signs of brain herniation caused by intracranial hypertension. Furthermore, available data indicate that a minimal and a mean CPP measured during intensive care are good predictors of outcome in survivors, but a target threshold to improve outcome has yet to be defined.

Some medical management strategies can have detrimental effects, and there is now a good case for undertaking a controlled trial of immediate or delayed craniectomy. Independent outcome in children following severe head injury is associated with higher levels of CPP. The ability to tolerate different levels of CPP may be related to age, and therefore any such surgical trial would need a carefully defined protocol so that the potential benefit of such a treatment is maximized.
\end{abstract}

\section{KEY WORDS - cerebral perfusion pressure - intracranial pressure • head injury • coma • child}

Severe head injury in children is still associated with significant mortality and morbidity rates despite advances in pediatric intensive care. ${ }^{95,105}$ The severity of the initial injury-usually assessed clinically based on GCS score, brainstem function, and/or systems designed to assess multiorgan failure, such as the Pediatric Risk of Mortality ${ }^{15}$ - is directly associated with the incidence of death. Nonetheless, many children with such injuries do survive with a good outcome, particularly if they have not experienced shock. ${ }^{68}$ Survival and long-term outcome may be better in children than in adults with low ICP following head injury, but patients in all age groups with ICPs higher than $20 \mathrm{~mm} \mathrm{Hg}$, whether treatable, have a worse outcome. ${ }^{2}$ Intracranial hypertension is thought to cause brain damage by at least two mechanisms. First, if there are differences in pressure between the forebrain and the posterior fossa, one or both temporal lobes may herniate through the tentorium, causing direct pressure as well as reduced blood flow in the brainstem ${ }^{104}$ and leading to brainstem

\footnotetext{
Abbreviations used in this paper: $\mathrm{CBF}=$ cerebral blood flow; $\mathrm{CPP}=$ cerebral perfusion pressure $\mathrm{CT}=$ computerized tomography; GCS = Glasgow Coma Scale; ICP = intracranial pressure; $\mathrm{MABP}=$ mean arterial blood pressure; $\mathrm{PICU}=$ pediatric intensive care unit.
}

death, unless the pressure difference is rapidly reversed. ${ }^{6}$ Second, reduced CPP, the difference between MABP and mean ICP, is associated with cortical and brainstem ischemia and poor outcome in survivors, including death. Systemic hypotension is also a feature of traumatic coma in pediatric patients, and consequently CPP may be reduced for variable periods. ${ }^{58,93,96}$ Currently, however, there is no consensus on the level at which CPP should be maintained to optimize outcome in children with head injury.

There are specific problems in studying the pediatric population. For example, normal values of blood pressure vary with age. Nonaccidental injury is an extremely important cause of seizures, focal neuropathology, and coma in the 1st year of life ${ }^{13}$ and should not be forgotten as a potential origin of injury in older children. To date, most studies have been retrospective in design and have been focused on short-term outcomes, usually morbidity, because long-term follow up of survivors is difficult and expensive. In this report, we review the available data and pose strategies for future studies.

\section{ACUTE PHASE OF INJURY}

The severity of an injury has an important effect on early survival. Poor outcome, particularly death, is associ- 
ated with a low GCS score, ${ }^{15,63,64,129}$ absent brainstem function, ${ }^{78,97}$ and multiple trauma. ${ }^{63,64,75}$ A CT scan can also be an important predictor of patient outcome in its ability to demonstrate mass lesions or diffuse swelling. ${ }^{42,73,101}$ After severe head injury, ICP is often raised due to either mass lesions such as extradural, subdural, or intracerebral hemorrhage, which are present in approximately one quarter of severely head injured children, ${ }^{2}$ or diffuse swelling. ${ }^{3,61}$ Patients with rapidly treated extradural or subdural hemorrhage may fare as well as those with nondiagnostic CT scans, ${ }^{42}$ although not in all cases..$^{63}$ Those with intraparenchymal or intraventricular hemorrhage or diffuse swelling have an increased chance of disability as well as death. ${ }^{33,34,42,66}$ Evidence-based guidelines for the evacuation of intraparenchymal hematomas have not yet been established for children. ${ }^{71}$ Cerebral blood flow may be significantly reduced as ICP rises, and cerebral metabolic rate and cerebral oxygen extraction are maximal shortly after injury in children. ${ }^{115}$ This means that the brain is very vulnerable to ischemic injury at this stage. Severe early intracranial hypertension may be associated with brain death within a few hours, ${ }^{92}$ although a good outcome is possible in such cases. ${ }^{99}$ Many children also experience hypotension immediately following an injury, either as a direct effect of head injury or due to hemorrhage. ${ }^{93}$ Hypotension is an important predictor of outcome, ${ }^{19,66,69,96}$ although improvements in emergency management procedures have enabled some patients who have experienced shock to survive. ${ }^{63}$ The average initial blood pressure in head-injured children is higher than normal levels in agematched children. ${ }^{28}$ Although there is an absolute requirement to raise blood pressure in children whose level falls below the 5th percentile for their age and there is a good case for volume expansion and/or vasopressors in those with normal blood pressure for their age, ${ }^{135}$ these principles are not advocated by all. ${ }^{12,50}$ Many patients suffer other secondary brain insults ${ }^{20}$ (for example, coagulopathy ${ }^{132}$ and hyperglycemia ${ }^{21}$ ) before they receive intensive care, and these insults may influence outcome. Hypoxia may be more highly associated with poor outcome in survivors $^{78}$ than death, ${ }^{96}$ although this assertion is controversial. ${ }^{91}$ In addition, anemia may play a role in patient outcome. $^{72}$ The effect of early posttraumatic seizures on morbidity and death is uncertain: they were associated with survival in one series ${ }^{135}$ and poor outcome in another. ${ }^{21}$ Prophylactic therapy may be associated with reduced mortality rates. ${ }^{130}$ Emergency care should be organized to optimize CPP during the golden hour immediately following head injury given that there is some evidence that this is beneficial. For example, the length of time between injury and admission to the PICU appeared to influence outcome in survivors in one series. ${ }^{21}$

\section{PROLONGED INTENSIVE CARE}

Most patients with who survive the first few hours after severe head injury require several days of intensive care, and ICP is usually measured during this time. ${ }^{74,113}$ The clinical and physiological variables on admission are less predictive of the level of disability in survivors. Instead, the GCS score 24 to 72 hours after injury is a better predictor of good outcome. ${ }^{18,78}$ Although children develop multiorgan failure less often than adults,,$^{14}$ those with multiple injuries, particularly if the chest is involved, are vulnerable to secondary insults such as hypotension and hypoxia. ${ }^{78}$ In one series delayed injury was documented on a CT scan in $41 \%$ of patients ${ }^{122}$ and was associated with multiple injuries and clotting disorders. Other possible mechanisms of secondary or progressive injury which may be associated with intracranial hypertension include arterial stroke (caused by carotid artery or vertebral artery dissection), ${ }^{10,32,110}$ venous sinus thrombosis, ${ }^{123,126}$ vasospasm, ${ }^{7}$ and seizures. ${ }^{81}$

\section{PATHOPHYSIOLOGICAL FEATURES}

Both ICP and CPP may remain stable for long periods of time in unconscious patients, but may then fluctuate unexpectedly. There are several mechanisms that maintain $\mathrm{CBF}$ in the face of changing blood pressure and increased oxygen extraction when CPP is low. Autoregulation is the most crucial of these mechanisms important in compensating for temporary derangement in normal brain tissue and is apparently preserved in the majority of head-injured children ${ }^{85,114}$ Note, however, that failure of autoregulation has been associated with poor outcome. ${ }^{114}$ Any attempt to define an optimal level of CPP for an individual patient of any age must therefore take this pathophysiology into account, even if it cannot be measured in a particular patient.

Sustained plateau or A waves were first described by Lundberg, et al., ${ }^{70}$ but not until much later was the vasodilatory cascade hypothesis put forward by Rosner and Becker ${ }^{107}$ to explain their occurrence. These latter investigators asserted that CPP may be unstable at values between approximately 50 and $90 \mathrm{~mm} \mathrm{Hg}$. When MABP (or CPP) is high, most of the resistance occurring in response to a change in pressure takes place in the larger $(>200 \mu \mathrm{m})$ pial and intracerebral vessels; however, at values lower than $90 \mathrm{~mm} \mathrm{Hg}$, the smaller $(<100 \mu \mathrm{m})$ cerebral vessels also dilate. Although autoregulation may be preserved, slight decreases in blood pressure are associated with rapid vasodilation causing marked increases in cerebral blood volume and therefore in ICP. ${ }^{107}$ In adults, ICP plateau waves did not occur at CPP values higher than $90 \mathrm{~mm} \mathrm{Hg}$. The plateau waves are usually self-limiting because the vessels reach maximal dilation and a compensatory Cushing response increases $\mathrm{CBF}$ and ICP initially. The increase in MABP causes vasoconstriction and then a decrease in ICP. The Cushing response is variable and may fail after a series of pressure waves ${ }^{62}$ or, if the systemic circulation is compromised, because of poor cardiac function or fluid restriction. ${ }^{108}$

As CPP decreases below the lower limit of autoregulation, that is, between 40 and $60 \mathrm{~mm} \mathrm{Hg},{ }^{79,134}$ oxygen extraction increases. ${ }^{49}$ Eventually, if CPP declines further, the vessels become maximally dilated (vasoparalysis) and they cannot respond to any increase in metabolic demand by increasing CBF. As a result, ischemia will occur if the capacity to increase oxygen extraction has been exceeded. The precise values for CPP at which these changes occur are uncertain and may vary in different circumstances, depending, for example, on whether there has been a recent previous plateau wave or seizure. At values of CPP less than $30 \mathrm{~mm} \mathrm{Hg}$, the vessels collapse and there is severe and irreversible ischemia. 


\section{MONITORING ICP AND CPP IN CHILDREN}

In pediatric head trauma, although it is clear that potentially avoidable secondary insults are common, ${ }^{16,47}$ as they are in adults, ${ }^{48}$ defining an optimal CPP to avoid them remains an area in which there is no absolute consensus. Children's blood pressure levels are normally lower, but there are very few data on normal levels of ICP in children; thus a normal level of CPP must be derived. ${ }^{47}$ There are very few studies in which investigators have looked at using ICP or CPP for the prediction of survival or outcome in pediatric patients with coma (traumatic or nontraumatic). Those that are available are relatively small and include patients with different mechanisms of injury (focal or diffuse) and treatment strategies for sustained intracranial hypertension; thus, determining a level of ICP or CPP at which corrective action should be taken is very difficult.

\section{Intracranial Pressure, CPP, and the Prediction of Death}

Although defining a safe threshold has proved elusive, several authors have shown that ICP and CPP measurements from long-term monitoring are good predictors of death in pediatric patients with traumatic coma. ${ }^{17,31,40,47,56,99,125}$ In one series, a sustained ICP greater than $60 \mathrm{~mm} \mathrm{Hg}$ was associated with death in all patients; there was only one survivor among those with a prolonged ICP higher than $50 \mathrm{~mm} \mathrm{Hg}$ and that patient was disabled. ${ }^{99}$ In another study, a lower mean ICP was associated with survival. ${ }^{135}$ Data from this study also indicated that survival was more likely in those with a maximal systolic blood pressure greater than $135 \mathrm{~mm} \mathrm{Hg}$, although previous studies have demonstrated that hypertension may be associated with poor outcome in survivors. ${ }^{12,50}$ In a very large series focused on adults and children, Luerssen, et al., ${ }^{69}$ found hypotension to be a good predictor of death; children with hypertension had the best outcome compared with adults, who fared best with normal blood pressure.

A mean CPP less than $40 \mathrm{~mm} \mathrm{Hg}$ predicted death in all children in one study. ${ }^{31}$ These results agree with Changaris and colleagues' ${ }^{18}$ data, which demonstrated that a mean CPP less than $40 \mathrm{~mm} \mathrm{Hg}$ on Day 1 in adults and in children as young as 3 years of age, predicted death. These authors also found that patients with a mean CPP of less than $60 \mathrm{~mm} \mathrm{Hg}$ for longer than 8 hours on Day 2 postinjury had a higher mortality rate. There is considerable discrepancy in the threshold reported in different series. For example, Hackbarth, et al., ${ }^{40}$ found that the inability to maintain a CPP greater than $50 \mathrm{~mm} \mathrm{Hg}$ on the 1 st day in the PICU appeared to predict death, whereas in the series of Jones and colleagues, ${ }^{47}$ death was associated with a wider mean range of CPP, that is, 2 to $65 \mathrm{~mm} \mathrm{Hg}$.

\section{Cerebral Perfusion Pressure and the Prediction of Morbidity in Survivors}

There are few data on the prediction of outcome in survivors. A minimal CPP of less than $30 \mathrm{~mm} \mathrm{Hg}$ sustained for more than a few minutes is rarely compatible with intact survival, whatever the origin of injury. ${ }^{36}$ Nonetheless, in the absence of published data, it would be unwise to use any specific cutoff in terms of the minimal CPP or duration of low CPP to make decisions about the withdrawal of treatment in an individual patient, especially given that good outcome has been documented in patients with a minimal CPP of less than $30 \mathrm{~mm} \mathrm{Hg}$ for a short time period (unpublished data). ${ }^{30,37}$ Additional information about a likely prognosis may be obtained at the patient's bedside by using neurophysiological or CBF techniques. ${ }^{53,54}$

In a combined series of head-injured adults and children, Changaris, et al., ${ }^{18}$ found that a mean CPP higher than $90 \mathrm{~mm} \mathrm{Hg}$ on Day 2 postinjury was associated with a good outcome, but they also acknowledged that children might be able to tolerate a lower mean CPP, although a threshold was not defined. A better outcome in survivors has been associated with a higher mean and minimal CPP in most $^{16,47,56}$ but not all ${ }^{125}$ series involving pediatric patients. Regardless, the recommended safe level has varied, perhaps because of differences in the patient populations or the methods of analysis.

In one of the few studies with a long-term follow up of the survival of children following head injury (50 patients), Kieslich and colleagues ${ }^{52}$ found that of 17 children with a minimal CPP less than $50 \mathrm{~mm} \mathrm{Hg}$, two thirds had moderate or severe disability. Jones, et al., ${ }^{47}$ noted that the duration of age-specific disruption in CPP was the best predictor of outcome and that a reduction in CPP was commonly caused by a decrease in MABP as well as an increase in ICP. These authors asserted that attempting to maintain CPP within the physiological range for age might improve outcome. Chambers, et al., ${ }^{17}$ who used receiver-operator curves, examined the sensitivity and specificity of ICP and CPP in relation to independent outcome in 84 children with head injury. These investigators proposed that, although it was necessary to allow for unexpected fluctuations and measurement errors, the minimal acceptable CPP might be lower in children $(60 \mathrm{~mm}$ $\mathrm{Hg}$ rather than the $70 \mathrm{~mm} \mathrm{Hg}$ recommended for adults). ${ }^{109}$ In fact, there are data from adults with traumatic coma indicating that a CPP of greater than $60 \mathrm{~mm} \mathrm{Hg}$ has little influence on outcome. ${ }^{48}$ Chambers and coworkers ${ }^{16}$ and Jones and colleagues ${ }^{47}$ asserted that in children with diffuse head injury and in whom sudden increases in ICP were relatively rare, it might be more important to measure blood pressure than ICP. This may also be the case in infants who have been nonaccidentally injured, especially given that in this group, minimal CPP and MABP were related to outcome, but maximal ICP was not. ${ }^{9}$

There are also pertinent data from patients with nontraumatic coma. Tasker, et al., ${ }^{127}$ found in a group of children unconscious for a variety of reasons that those with a minimal CPP of less than $38 \mathrm{~mm} \mathrm{Hg}$ all fared very poor$1 y$, but that there were some patients with a poor outcome in whom a CPP below this value was not noted. There is evidence that a high ICP and a low CPP are also associated with a poor prognosis in Reye syndrome, ${ }^{46}$ hepatic failure, ${ }^{5}$ central nervous system infections, ${ }^{36,53,82,87,88,103}$ and focal $^{81}$ and global ischemia (including that from near drowning). 11,53,65,90,111 In a series including children with traumatic and nontraumatic coma, the mean CPP during the entire monitoring period was the only variable that predicted survival and good outcome. ${ }^{56} \mathrm{~A}$ mean CPP less 
than 65 and $50 \mathrm{~mm} \mathrm{Hg}$ during the first 6 hours predicted poor outcome and death, respectively. ${ }^{56}$

\section{MANAGEMENT OF CPP}

\section{Medical Therapy}

It has proved more difficult to show that improving CPP advances outcome with currently available medical management. It is generally agreed that a child should be nursed flat, with his or her head in the midline (so that venous drainage from the head is not obstructed) and his or her head positioned either flat or tilted up to $30^{\circ}$. The patient should be handled as little as possible, and nursing procedures such as suction should be performed with caution.

Unfortunately, many of the techniques for reducing ICP rapidly in an emergency have detrimental effects when used over a longer time period, and there are very few data from randomized controlled trials in children with outcome in survivors as the end point. Controlled trials of medical treatment for intracranial hypertension have been conducted mainly in adults with head injuries, but these have demonstrated no overall benefit of treatment with steroid or barbiturate agents, hyperventilation, or hypothermia. There is no evidence that prophylactic hyperventilation prevents intracranial hypertension, ${ }^{84}$ but there is evidence that CBF may be reduced below the ischemic threshold with the aid of hypocapnia in unconscious children. ${ }^{119}$ Fluid restriction has been shown to be potentially harmful in children with meningitis. ${ }^{100}$ Mannitol may reduce spikes of ICP very rapidly and acts either as an osmotic diuretic or by reducing cerebral blood volume. As with hyperventilation therapy, there is no evidence that the regular prophylactic use of mannitol is beneficial, and results from one study showed an increase in the length of the PICU stay in patients who had received mannitol, with no evidence of improved outcome. ${ }^{135}$ Hypertonic saline may have advantages ${ }^{94}$ and has been associated with a decreased duration in the PICU stay in a randomized trial in children, ${ }^{117}$ but there are concerns that there is a risk of central pontine myelinolysis and long-term follow-up data are awaited.

For barbiturate coma, the risk of hypotension probably outweighs any useful effect in reducing ICP. Drug levels may remain high for several days after administration of the drug has been discontinued, making the clinical diagnosis of brain death impossible. Reducing body temperature, even by a small amount, reduces cerebral metabolic rate considerably, and there is evidence for an additional beneficial effect on ischemic brain tissue. One major advantage is that hypothermia is easily reversible. There is a risk of neutropenia and infection, ${ }^{11,45}$ but benefit has been indicated in head-injured patients, perhaps in reducing ICP rather than as a neuroprotective agent. ${ }^{44}$ Data from one controlled trial in adults revealed no benefit, ${ }^{24}$ possibly because of unexpected age and center differences and because patients in the hypothermia arm required increased fluids. The ongoing Hypothermia in Pediatric Head Injury Trial ${ }^{43}$ (a randomized controlled trial in children, which is also exploring the use of a wide range of outcome measures) will provide useful information.

In adults, two alternative strategies are currently proposed for the management of intractable intracranial hy- pertension. ${ }^{89,108,109,121}$ Rosner and colleagues ${ }^{108,109}$ suggested that medical strategies to reduce ICP and maintain CPP higher than $70 \mathrm{~mm} \mathrm{Hg}$ may improve outcome. There is evidence from nonrandomized studies in adults that patients with a CPP greater than $70 \mathrm{~mm} \mathrm{Hg}$ have a better outcome, but standardized protocols have been designed to maintain CPP above this level. The problem is that the evidence to support such a strategy is inconclusive. Robertson, et al., ${ }^{107}$ found that although cerebral ischemia was reduced using a similar protocol that included the maintenance of normocapnia, survival was not improved and adult respiratory distress syndrome was more common in the treatment arm. If autoregulation is preserved, increasing blood pressure does reduce ICP in children with head injury. ${ }^{85}$ Because children are relatively protected from multiorgan failure, maintenance of a relatively high CPP might improve neurological outcome without any increase in other complications; demonstrating this, however, requires definition of a target CPP in different age groups ${ }^{16,17,47}$ and a randomized trial. An alternative volume-targeted strategy has been proposed by Nordström and coworkers ${ }^{89,121}$ and involves the maintenance of a normal colloid osmotic pressure (with blood or albumin transfusion) in combination with a reduction in intracapillary hydrostatic pressure to encourage increased resorption of intracerebral water and therefore a reduction in cerebral edema. Note that there are few data on the efficacy of this management strategy in children.

\section{Surgical Management}

Mass lesions may require surgical treatment, and drainage of cerebrospinal fluid via the ventricular or lumbar route is probably beneficial, ${ }^{67}$ although there are few data proving this. Early clinical experience with radical craniectomy in the management of severe head injury was mixed, $26,51,57,102,116,133,137$ and enthusiasm was particularly dampened by the demonstration of increased cerebral edema experimentally ${ }^{25}$ and upward herniation of the human brain postmortem after circumferential craniectomy. ${ }^{23}$ Part of the discrepancy among study data may reflect the age of the patients, the timing of surgical decompression, the presence of a mass lesion such as a subdural hematoma, and the severity of brainstem compression as indicated by papillary responses or respiration. The original data were collected before advances in anesthetic agents, operative techniques, and intensive treatment of such patients.

Subtemporal decompression has also been advocated in patients who fail to respond to medical management. Alexander, et al., ${ }^{4}$ pointed out that one could expect an increase in intracranial volume of up to $33 \mathrm{~cm}^{3}$ from a subtemporal decompression. Gower, et al., ${ }^{38}$ looked at a retrospective series of patients with severe head injures who would not have been expected to survive because of a failure to respond to intensive treatment including chemoparalysis, hyperventilation, mannitol, or pentobarbital therapy. Ten patients who had undergone subtemporal decompression suffered substantially lower morbidity and mortality rates $(40 \%)$ compared with a group treated only with medical therapy $(82 \%)$.

Surgical decompression has continued to be performed by personnel in several centers by using a variety of techniques with variable results. This procedure was usually 
undertaken for signs of incipient transtentorial herniation within the first few hours postinjury or for intractable hypertension despite maximal medical therapy during intensive care. ${ }^{29,35,39,59,60,77,86,98,112}$ Social rehabilitation is certainly possible in these cases, ${ }^{1}$ and there has been a recent resurgence of interest in the use of decompressive craniectomy as part of a protocol for the early management of raised ICP in head injury. ${ }^{136}$ Given that signs such as pupillary dilation occur late in brainstem compromise,${ }^{6}$ it would be more helpful to use early physiological measurements (CPP and ICP) rather than clinical signs or imaging studies, whose direct relationship to ICP is problematic. In one series, craniectomy reduced intraventricular pressure by mean of $50 \%$, and opening the dura mater further reduced intraventricular pressure by $35 \% .{ }^{138}$ Monitoring of ICP and tissue oxygenation may give sufficient warning of impending deterioration to allow for a later craniectomy. ${ }^{124}$

For a number of reasons, including the ethical dilemma of obtaining consent in the acute phase following head injury and a lack of consensus on the criteria for the most appropriate procedure, randomized controlled trials have proved very difficult to organize. Although young age is one of the best predictors of good outcome, children may be excluded from future studies, in part because there are few data on the relationship among ICP, CPP, and outcome in this group. Results of several case series have demonstrated a benefit from unilateral and bilateral edema for traumatic ${ }^{27,41,83,117,118,120}$ and nontraumatic ${ }^{8,53-56,76,80} \mathrm{coma}$ in the pediatric population, including those with an ICP greater than $30 \mathrm{~mm} \mathrm{Hg}$ in the context of a subdural hematoma after a shaking injury. ${ }^{22} \mathrm{~A}$ recent randomized controlled trial of early craniectomy after head trauma in a pediatric population ${ }^{128}$ appeared to show a clear benefit, with seven of 13 patients remaining independent after craniectomy compared with two of 14 patients randomized to conventional treatment. Nonetheless, questions remain about the interpretation and extrapolation of data from this small pilot study, including the precise indications for craniectomy, inclusion and exclusion criteria, the best operation to perform, and whether the dura should be opened. To plan a trial that would include a pediatric population (Randomised Evaluation of Surgery with Craniectomy), ${ }^{131}$ perhaps in which were compared surgical decompression with a protocol to maximize blood pressure, the ICP and CPP thresholds that could distinguish good from poor outcome in children of different ages must be determined.

\section{CONCLUSIONS}

In conclusion, independent outcome in children following severe head injury is associated with higher levels of CPP. Note, however, that the sensitivity of both CPP and ICP may vary with age and that younger children may be able to tolerate lower levels of CPP and/or higher levels of ICP while still achieving independent outcomes. Further research in this important area is urgently needed to increase the evidence base for clinical practice.

\section{References}

1. Albanese J, Leone M, Alliez JR, et al: Decompressive craniectomy for severe traumatic brain injury: Evaluation of the effects at one year. Crit Care Med 31:2535-2538, 2003
2. Alberico AM, Ward JD, Choi SC, et al: Outcome after severe head injury. Relationship to mass lesions, diffuse injury, and ICP course in pediatric and adult patients. J Neurosurg 67: 648-656, 1987

3. Aldrich EF, Eisenberg HM, Saydjari C, et al: Diffuse brain swelling in severely head-injured children. A report from the NIH Traumatic Coma Data Bank. J Neurosurg 76:450-454, 1992

4. Alexander E, Ball MR, Laster DW: Subtemporal decompression: radiological observations and current surgical experience. Br J Neurosurg 1:427-433, 1987

5. Alper G, Jarjour IT, Reyes JD, et al: Outcome of children with cerebral edema caused by fulminant hepatic failure. Pediatr Neurol 18:299-304, 1998

6. Ammar A, Awada A, al-Luwami I: Reversibility of severe brain stem dysfunction in children. Acta Neurochir 124: 86-91, 1993

7. Aparicio JM, Tavares C, Teixeira-Pinto A, et al: Cerebral vasospasm in pediatric head injuries: transcranial Doppler ultrasound findings. Cerebrovasc Dis 11 (Suppl 3):38, 2001 (Abstract)

8. Ausman JI, Rogers C, Sharp HL: Decompressive craniectomy for the encephalopathy of Reye's syndrome. Surg Neurol 6: 97-99, 1976

9. Barlow KM, Minns RA: The relationship between intracranial pressure and outcome in non-accidental head injury. Dev Med Child Neurol 41:220-225, 1999

10. Biffl WL, Moore EE, Offner PJ, et al: Blunt carotid arterial injuries: implications of a new grading scale. J Trauma 47: 845-853, 1999

11. Bohn DJ, Biggar WD, Smith CR, et al: Influence of hypothermia, barbiturate therapy, and intracranial pressure monitoring on morbidity and mortality after near-drowning. Crit Care Med 14:529-534, 1986

12. Brink JD, Imbus C, Woo-Sam J: Physical recovery after severe closed head trauma in children and adolescents. J Pediatr 97:721-727, 1980

13. Brown JK, Minns RA: Non-accidental head injury, with particular reference to whiplash shaking injury and medico-legal aspects. Dev Med Child Neurol 35:849-869, 1993

14. Calkins CM, Bensard DD, Moore EE, et al: The injured child is resistant to multiple organ failure: a different inflammatory response? J Trauma 53:1058-1063, 2002

15. Cantais E, Paut O, Giorgi R, et al: Evaluating the prognosis of multiple, severely traumatized children in the intensive care unit. Intensive Care Med 27:1511-1517, 2001

16. Chambers IR, Treadwell L, Mendelow AD: The cause and incidence of secondary insults in severely head-injured adults and children. Br J Neurosurg 14:424-431, 2000

17. Chambers IR, Treadwell L, Mendelow AD: Determination of threshold levels of cerebral perfusion pressure and intracranial pressure in severe head injury by using receiver-operating characteristic curves: an observational study in 291 patients. J Neurosurg 94:412-416, 2001

18. Changaris DG, McGraw CP, Richardson JD, et al: Correlation of cerebral perfusion pressure and Glasgow outcome scale to outcome. J Trauma 27:1007-1012, 1987

19. Chesnut RM, Marshall LF, Klauber MR, et al: The role of secondary brain injury in determining outcome from severe head injury. J Trauma 34:216-222, 1993

20. Chiaretti A, De Benedictis R, Della Corte F, et al: The impact of initial management on the outcome of children with severe head injury. Childs Nerv Syst 18:54-60, 2002

21. Chiaretti A, Piastra M, Pulitano S, et al: Prognostic factors and outcome of children with severe head injury: an 8-year experience. Childs Nerv Syst 18:129-136, 2002

22. Cho DY, Wang YC, Chi CS: Decompressive craniotomy for acute shaken/impact baby syndrome. Pediatr Neurosurg 23: 192-198, 1995 
23. Clark K, Nash TM, Hutchison GC: The failure of circumferential craniotomy in acute traumatic cerebral swelling. J Neurosurg 29:367-371, 1968

24. Clifton GL, Miller ER, Choi SC, et al: Lack of effect of induction of hypothermia after acute brain injury. N Engl J Med 344:556-563, 2001

25. Cooper PR, Hagler H, Clark W, et al: Enhancement of experimental cerebral edema after decompressive craniectomy: implications for the management of severe head injuries. Neurosurgery 4:296-300, 1979

26. Cooper PR, Rovit RL, Ransohoff J: Hemicraniectomy in the treatment of acute subdural hematoma: a re-appraisal. Surg Neurol 5:25-28, 1976

27. Dam Hieu P, Sizun J, Person H, et al: The place of decompressive surgery in the treatment of uncontrollable post-traumatic intracranial hypertension in children. Childs Nerv Syst 12:270-275, 1996

28. Dark P, Woodford M, Vail A, et al: Systolic hypertension and the response to blunt trauma in infants and children. Resuscitation 54:245-253, 2002

29. De Luca GP, Volpin L, Fornezza U, et al: The role of decompressive craniectomy in the treatment of uncontrollable posttraumatic intracranial hypertension. Acta Neurochir Suppl 76: 401-404, 2000

30. Diesner F, Moskopp D, Schul C, et al: Short-term lack of cerebral perfusion with good outcome. Advantages of early intracranial pressure monitoring. Neurosurg Rev 20:274-277, 1997

31. Downard C, Hulka F, Mullins RJ, et al: Relationship of cerebral perfusion pressure and survival in pediatric brain-injured patients. J Trauma 49:654-659, 2000

32. Duke BJ, Partington MD: Blunt carotid injury in children. Pediatr Neurosurg 25:188-193, 1996

33. Fearnside MR, Cook RJ, McDougall P, et al: The Westmead Head Injury Project outcome in severe head injury. A comparative analysis of pre-hospital, clinical and CT variables. Br J Neurosurg 7:267-279, 1993

34. Feickert HJ, Drommer S, Heyer R: Severe head injury in children: impact of risk factors on outcome. J Trauma 47:33-38, 1999

35. Gaab MR, Rittierodt M, Lorenz M, et al: Traumatic brain swelling and operative decompression: a prospective investigation. Acta Neurochir Suppl 51:326-328, 1990

36. Goitein KJ, Amit Y, Mussaffi H: Intracranial pressure in central nervous system infections and cerebral ischaemia of infancy. Arch Dis Child 58:184-186, 1983

37. Golash A, O'Brien DPK, Thorne JA, et al: What is the acceptable cerebral perfusion pressure in children with severe brain injury? in The J Douglas Miller Memorial Meeting: October 16-18th, 1996, Edinburgh, Scotland, United Kingdom. Edinburgh: JDM, 1996, p P7-3 (Abstract)

38. Gower DJ, Lee KS, McWhorter JM: Role of subtemporal decompression in severe closed head injury. Neurosurgery 23: 417-422, 1988

39. Guerra WK, Piek J, Gaab MR: Decompressive craniectomy to treat intracranial hypertension in head injury patients. Intensive Care Med 25:1327-1329, 1999

40. Hackbarth RM, Rzeszutko KM, Sturm G, et al: Survival and functional outcome in pediatric traumatic brain injury: a retrospective review and analysis of predictive factors. Crit Care Med 30:1630-1635, 2002

41. Hejazi N, Witzmann A, Fae P: Unilateral decompressive craniectomy for children with severe brain injury. Report of seven cases and review of the relevant literature. Eur J Pediatr 161:99-104, 2002

42. Hirsch W, Schobess A, Eichler G, et al: Severe head trauma in children: cranial computer tomography and clinical consequences. Paediatr Anaesth 12:337-344, 2002

43. Hutchison J, Bohn D, Hebert P, et al: Hypothermia Pediatric Head Injury Trial (HyP-HIT). (http://www.cheori.org/Hyp-
HIT/hypothermia_in_pediatric_head_in.htm) [Accessed 13 November 2003]

44. Inamasu J, Ichikizaki K, Matsumoto S, et al: Mild hypothermia for hemispheric cerebral infarction after evacuation of an acute subdural hematoma in an infant. Childs Nerv Syst 18: 175-178, 2002

45. Ishikawa K, Tanaka H, Shiozaki T, et al: Characteristics of infection and leukocyte count in severely head-injured patients treated with mild hypothermia. J Trauma 49:912-922, 2000

46. Jenkins JG, Glasgow JF, Black GW, et al: Reye's syndrome: assessment of intracranial monitoring. Br Med J 294:337-338, 1987

47. Jones PA, Andrews PJD, Easton VJ, et al: Traumatic brain injury in childhood: intensive care time series data and outcome. Br J Neurosurg 17:29-39, 2003

48. Juul N, Morris GF, Marshall SB, et al: Intracranial hypertension and cerebral perfusion pressure: influence on neurological deterioration and outcome in severe head injury. The Executive Committee of the International Selfotel Trial. J Neurosurg 92: 1-6, 2000

49. Kanno I, Uemura K, Higano S, et al: Oxygen extraction fraction at maximally vasodilated tissue in the ischemic brain estimated from the regional $\mathrm{CO} 2$ responsiveness measured by positron emission tomography. J Cereb Blood Flow Metab 8: 227-235, 1988

50. Kanter RK, Carroll JB, Post EM: Association of arterial hypertension with poor outcome in children with acute brain injury. Clin Pediatr 24:320-323, 1985

51. Kerr FW: Radical decompression and dural grafting in severe cerebral edema. Mayo Clin Proc 43:852-864, 1968

52. Kieslich M, Marquardt G, Galow G, et al: Neurological and mental outcome after severe head injury in childhood: a longterm follow-up of 318 children. Disabil Rehabil 23:665-669, 2001

53. Kirkham FJ: Intracranial pressure and cerebral blood flow in non-traumatic coma in childhood, in Minns RA (ed): Problems of Intracranial Pressure in Childhood. New York: Oxford Mac Keith Press, 1991, pp 283-348

54. Kirkham FJ, Levin SD, Padayachee TS, et al: Transcranial pulsed Doppler ultrasound findings in brain stem death. J Neurol Neurosurg Psychiatry 50:1504-1513, 1986

55. Kirkham FJ, Neville BGR: Successful management of severe intracranial hypertension by surgical decompression. Dev Med Child Neurol 28:506-509, 1986

56. Kirkham FJ, Tasker RC, Lee M, et al: Intracranial and cerebral perfusion pressures in paediatric traumatic and non-traumatic coma: relationship to outcome. Dev Med Child Neurol 42 (Suppl 85):14, 2000 (Abstract)

57. Kjellberg RN, Prieto A Jr: Bifrontal decompressive craniotomy for massive cerebral edema. J Neurosurg 34:488-493, 1971

58. Kokoska ER, Smith GS, Pittman T, et al: Early hypotension worsens neurological outcome in pediatric patients with moderately severe head trauma. J Pediatr Surg 33:333-338, 1998

59. Kontopoulos V, Foroglou N, Patsalas J, et al: Decompressive craniectomy for the management of patients with refractory hypertension: should it be reconsidered? Acta Neurochir 144: 791-796, 2002

60. Kunze E, Meixensberger J, Janka M, et al: Decompressive craniectomy in patients with uncontrollable intracranial hypertension. Acta Neurochir Suppl 71:16-18, 1998

61. Lang DA, Teasdale GM, Macpherson P, et al: Diffuse brain swelling after head injury: more often malignant in adults than children? J Neurosurg 80:675-680, 1994

62. Langfitt TW, Weinstein JD, Kassell NF: Cerebral vasomotor paralysis produced by intracranial hypertension. Neurology 15: 622-641, 1965

63. Levi L, Guilburd JN, Bar-Yosef G, et al: Severe head injury in children - analyzing the better outcome over a decade and the role of major improvements in intensive care. Childs Nerv Syst 14:195-202, 1998 
64. Levi L, Guilburd JN, Linn S, et al: The association between skull fracture, intracranial pathology and outcome in pediatric head injury. Br J Neurosurg 5:617-625, 1991

65. Le Roux PD, Jardine DS, Kanev PM, et al: Pediatric intracranial pressure monitoring in hypoxic and nonhypoxic brain injury. Childs Nerv Syst 7:34-39, 1991

66. Levin HS, Aldrich EF, Saydjari C, et al: Severe head injury in children: experience of the Traumatic Coma Data Bank. Neurosurgery 31:435-444, 1992

67. Levy DI, Rekate HL, Cherny WB, et al: Controlled lumbar drainage in pediatric head injury. J Neurosurg 83:453-460, 1995

68. Lieh-Lai MW, Theodorou AA, Sarnaik AP, et al: Limitations of the Glasgow Coma Scale in predicting outcome in children with traumatic brain injury. J Pediatr 120:195-199, 1992

69. Luerssen TG, Klauber MR, Marshall LF: Outcome from head injury related to patient's age. A longitudinal prospective study of adult and pediatric head injury. J Neurosurg 68:409-416, 1988

70. Lundberg N, Troupp H, Lorin H: Continuous recording of the ventricular-fluid pressure in patients with severe acute traumatic brain injury. A preliminary report. J Neurosurg 22:581-590, 1965

71. Mandera M, Zralek C, Krawczyk I, et al: Surgery or conservative treatment in children with traumatic intracerebral haematoma. Childs Nerv Syst 15:267-270, 1999

72. Marescal C, Adnet P, Bello N, et al: Secondary cerebral stress of systemic origin in children with severe craniocerebral injuries. Ann Fr Anesth Reanim 17:234-239, 1998

73. Marshall LF, Marshall SB, Klauber MR, et al: The diagnosis of head injury requires a classification based on computed axial tomography. J Neurotrauma 9 (Suppl 1):S287-S292, 1992

74. Mayer T, Walker ML: Emergency intracranial pressure monitoring in pediatrics: management of the acute coma of brain insult. Clin Pediatr 21:391-396, 1982

75. Mayer T, Walker ML, Shasha I, et al: Effect of multiple trauma on outcome of pediatric patients with neurologic injuries. Childs Brain 8:189-197, 1981

76. McLaurin RL, Nichols JB Jr: Extensive cranial decompression in the treatment of severe lead encephalopathy. Pediatrics 20: 653-667, 1957

77. Meier U, Zeilinger FS, Henzka O: The use of decompressive craniectomy for the management of severe head injuries. Acta Neurochir Suppl 76:475-478, 2000

78. Michaud LJ, Rivara FP, Grady MS, et al: Predictors of survival and severity of disability after severe brain injury in children. Neurosurgery 31:254-264, 1992

79. Miller JD, Stanek A, Langfitt TW: Concepts of cerebral perfusion pressure and vascular compression during intracranial hypertension. Prog Brain Res 35:411-432, 1972

80. Millman G, Thompson D, Kirkham FJ: Surgical decompression for malignant middle cerebral artery territory infarction in childhood. Dev Med Child Neurol 40 (Suppl 79):24, 1998 (Abstract)

81. Minns RA, Brown JK: Intracranial pressure changes associated with childhood seizures. Dev Med Child Neurol 20: 561-569, 1978

82. Minns RA, Engleman HM, Stirling H: Cerebrospinal fluid pressure in pyogenic meningitis. Arch Dis Child 64:814-820, 1989

83. Morgalla MH, Krasznai L, Buchholz R, et al: Repeated decompressive craniectomy after head injury in children: two successful cases as result of improved neuromonitoring. Surg Neurol 43:583-590, 1995

84. Muizelaar JP, Marmarou A, Ward JD, et al: Adverse effects of prolonged hyperventilation in patients with severe head injury: a randomized clinical trial. J Neurosurg 75:731-739, 1991

85. Muizelaar JP, Ward JD, Marmarou A, et al: Cerebral blood flow and metabolism in severely head-injured children. Part 2: Autoregulation. J Neurosurg 71:72-76, 1989

86. Münch E, Horn P, Schürer L, et al: Management of severe trau- matic brain injury by decompressive craniectomy. Neurosurgery 47:315-323, 2000

87. Newton CR, Crawley J, Sowumni A, et al: Intracranial hypertension in Africans with cerebral malaria. Arch Dis Child 76: 219-226, 1997

88. Newton CR, Kirkham FJ, Winstanley PA, et al: Intracranial pressure in African children with cerebral malaria. Lancet 337: 573-576, 1991

89. Nordström CH, Reinstrup $\mathrm{P}, \mathrm{Xu} \mathrm{W}$, et al: Assessment of the lower limit for cerebral perfusion pressure in severe head injuries by bedside monitoring of regional energy metabolism. Anesthesiology 98:809-814, 2003

90. Nussbaum E, Galant SP: Intracranial pressure monitoring as a guide to prognosis in the nearly drowned, severely comatose child. J Pediatr 102:215-218, 1983

91. Ong L, Selladurai BM, Dhillon MK, et al: The prognostic value of the Glasgow Coma Scale, hypoxia and computerised tomography in outcome prediction of pediatric head injury. Pediatr Neurosurg 24:285-291, 1996

92. Papo I, Caruselli G, Luongo A: Intracranial pressure in children and adolescents with severe head injuries. J Neurosurg Sci 26:193-198, 1982

93. Patrick DA, Bensard DD, Janik JS, et al: Is hypotension a reliable indicator of blood loss from traumatic injury in children? Am J Surg 184:555-560, 2002

94. Peterson B, Khanna S, Fisher B, et al: Prolonged hypernatremia controls elevated intracranial pressure in head-injured pediatric patients. Crit Care Med 28:1136-1143, 2000

95. Pfenninger J, Santi A: Severe traumatic brain injury in children-are the results improving? Swiss Med Wkly 132: 116-120, 2002

96. Pigula FA, Wald SL, Shackford SR, et al: The effect of hypotension and hypoxia on children with severe head injuries. J Pediatr Surg 28:310-314, 1993

97. Pillai S, Praharaj SS, Mohanty A, et al: Prognostic factors in children with severe diffuse brain injuries: a study of 74 patients. Pediatr Neurosurg 34:98-103, 2001

98. Polin RS, Shaffrey ME, Bogaev CA, et al: Decompressive bifrontal craniectomy in the treatment of severe refractory posttraumatic cerebral edema. Neurosurgery 41:84-94, 1997

99. Pople IK, Muhlbauer MS, Sanford RA, et al: Results and complications of intracranial pressure monitoring in 303 children. Pediatr Neurosurg 23:64-67, 1995

100. Powell KR, Sugarman LI, Eskenazi AE, et al: Normalization of plasma arginine vasopressin concentrations when children with meningitis are given maintenance plus replacement fluid therapy. J Pediatr 117:515-522, 1990

101. Prasad MR, Ewing-Cobbs L, Swank PR, Kramer L. Predictors of outcome following traumatic brain injury in young children. Pediatr Neurosurg 36:64-74, 2002

102. Ransohoff J, Benjamin MV, Gage EL Jr, et al: Hemicraniectomy in the management of acute subdural hematoma. J Neurosurg 34:70-76, 1971

103. Rebaud P, Berthier JC, Hartemann E, et al: Intracranial pressure in childhood central nervous system infections. Intensive Care Med 14:522-525, 1988

104. Ritter A, Muizelaar JP, Barnes T, et al: Brain stem blood flow, pupillary response, and outcome in patients with severe injuries. Neurosurgery 44:941-948, 1999

105. Robertson CM, Joffe AR, Moore AJ, et al: Neurodevelopmental outcome of young pediatric intensive care survivors of serious brain injury. Pediatr Crit Care Med 3: 345-350, 2002

106. Robertson CS, Valadka AB, Hannay HJ, et al: Prevention of secondary ischemic insults after severe head injury. Crit Care Med 27:2086-2095, 1999

107. Rosner MJ, Becker DP: Origin and evolution of plateau waves. Experimental observations and a theoretical model. J Neurosurg 60:312-324, 1984

108. Rosner MJ, Daughton S: Cerebral perfusion pressure management in head injury. J Trauma 30:933-941, 1990 
109. Rosner MJ, Rosner SD, Johnson AH: Cerebral perfusion pressure: management protocol and clinical results. J Neurosurg 83:949-962, 1995

110. Rutherfoord GS, Dada MA, Nel JP: Cerebral infarction and intracranial arterial dissection in closed head injury. Am J Forensic Med Pathol 17:53-57, 1996

111. Sarnaik AP, Preston G, Lieh-Lai M, et al: Intracranial pressure and cerebral perfusion pressure in near-drowning. Crit Care Med 13:224-227, 1985

112. Schneider GH, Bardt T, Lanksch WR, et al: Decompressive craniectomy following traumatic brain injury: ICP, CPP and neurological outcome. Acta Neurochir Suppl 81:77-79, 2002

113. Segal S, Gallagher AC, Shefler AG, et al: Survey of the use of intracranial pressure monitoring in children in the United Kingdom. Intensive Care Med 27:236-239, 2001

114. Sharples PM, Matthews DS, Eyre JA: Cerebral blood flow and metabolism in children with severe head injuries. Part 2: Cerebrovascular resistance and its determinants. J Neurol Neurosurg Psychiatry 58:153-159, 1995

115. Sharples PM, Stuart AG, Matthews DS, et al: Cerebral blood flow and metabolism in children with severe head injury. Part 1: Relation to age, Glasgow coma score, outcome, intracranial pressure, and time after injury. J Neurol Neurosurg Psychiatry 58:145-152, 1995

116. Shigemori M, Syojima K, Nakayama K, et al: The outcome from acute subdural haematoma following decompressive hemicraniectomy. Acta Neurochir 54:61-69, 1980

117. Simma B, Burger R, Falk M, et al: A prospective, randomized, and controlled study of fluid management in children with severe head injury: lactated Ringer's solution versus hypertonic saline. Crit Care Med 26:1265-1270, 1998

118. Simma B, Tscharre A, Hejazi N, et al: Neurologic outcome after decompressive craniectomy in children. Intensive Care Med 28:1000, 2002

119. Skippen P, Seear M, Poskitt K, et al: Effect of hyperventilation on regional cerebral blood flow in head-injured children. Crit Care Med 25:1402-1409, 1997

120. Sörensen N, Gaab M, Gruss P, et al: Decompressive craniectomy, an ultimate therapy in craniocerebral trauma. Monogr Paediatr 15:96-99, 1982

121. Stâhl N, Ungerstedt U, Nordström CH: Brain energy metabolism during controlled reduction of cerebral perfusion pressure in severe head injuries. Intensive Care Med 27:1215-1223, 2001

122. Stein SC, Spettell CM: Delayed and progressive brain injury in children and adolescents with head trauma. Pediatr Neurosurg 23:299-304, 1995

123. Stiefel D, Eich G, Sacher P: Posttraumatic dural sinus thrombosis in children. Eur J Pediatr Surg 10:41-44, 2000

124. Strege RJ, Lang EW, Stark AM, et al: Cerebral edema leading to decompressive craniectomy: an assessment of the preceding clinical and neuromonitoring trends. Neurol Res 25:510-515, 2003

125. Struthers SL, Lee MT, Marden B, et al: Severe traumatic brain injury and cerebral perfusion pressure in children. Intensive Care Med 27 (Suppl 2):S264, 2001

126. Taha JM, Crone KR, Berger TS, et al: Sigmoid sinus thrombosis after closed head injury in children. Neurosurgery 32: 541-546, 1993

127. Tasker RC, Matthew DJ, Helms $\mathrm{P}$, et al: Monitoring in nontraumatic coma. Part I: Invasive intracranial measurements. Arch Dis Child 63:888-894, 1988

128. Taylor A, Butt W, Rosenfeld J, et al: A randomized trial of very early decompressive craniectomy in children with traumatic brain injury and sustained intracranial hypertension. Childs Nerv Syst 17:154-162, 2001

129. Thakker JC, Splaingard M, Zhu J, et al: Survival and functional outcome of children requiring endotracheal intubation during therapy for severe traumatic brain injury. Crit Care Med 25:1396-1401, 1997

130. Tilford JM, Simpson PM, Yeh TS, et al: Variation in therapy and outcome for pediatric head trauma patients. Crit Care Med 29:1056-1061, 2001

131. University of Cambridge Department of Neurosurgery/Neurointensive Care, European Brain Injury Consortium: RESCUEicp study. Randomised Evaluation of Surgery with Craniectomy for Uncontrollable Elevation of Intra-Cranial Pressure. (http://www.brainit.org/brainit/brainit/downloads/ The \%20RESCUEicp\%20study\%20\%20protocol.doc) [Accessed 13 November 2003]

132. Vavilala MS, Dunbar PJ, Rivara FP, et al: Coagulopathy predicts poor outcome following head injury in children less than 16 years of age. J Neurosurg Anesthesiol 13:13-18, 2001

133. Venes JL, Collins WJ: Bifrontal decompressive craniectomy in the management of head trauma. J Neurosurg 42:429-433, 1975

134. Wagner EM, Traystman RJ: Hydrostatic determinants of cerebral perfusion. Crit Care Med 14:484-490, 1986

135. White JR, Farukhi Z, Bull C, et al: Predictors of outcome in severely head-injured children. Crit Care Med 29:534-540, 2001

136. Whitfield PC, Patel H, Hutchinson PJ, et al: Bifrontal decompressive craniectomy in the management of posttraumatic intracranial hypertension. Br J Neurosurg 15:500-507, 2001

137. Yamaura A, Uemura K, Makino $\mathrm{H}$ : Large decompressive craniectomy in management of severe cerebral contusion. A review of 207 cases. Neurol Med Chir 19:717-728, 1979

138. Yoo DS, Kim DS, Cho KS, et al: Ventricular pressure monitoring during bilateral decompression with dural expansion. J Neurosurg 91:953-959, 1999

Manuscript received October 31, 2003.

Accepted in final form November 12, 2003.

Address reprint requests to: Iain R. Chambers, Ph.D., Regional Medical Physics Department, Newcastle General Hospital, Westgate Road, Newcastle Upon Tyne; NE4 6BE, United Kingdom. email: i.r.chambers@ncl.ac.uk. 